Journal of Al Azhar University Engineering Sector

Vol. 14, No. 52, July 2019, 891-902

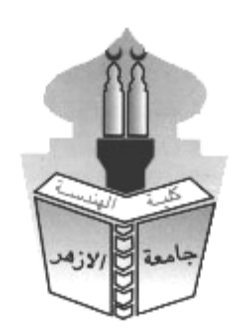

\title{
NUMERICAL AND EXPERIMENTAL STUDY OF A SMALL-SCALE SLIDING VANE PUMP
}

\author{
Ahmed H. El-Hennawi, Nabil A. Mahmoud, Ahmed E. Hussin and Ashraf M. Hamed \\ Department of Mechanical Engineering, Ain Shams University, \\ Email: 9525@eng.asu.edu.eg
}

\begin{abstract}
Automotive pumps have two forms either hydraulic or centrifugal one. Hydraulic pumps are usually positive displacement pumps. In the automotive industry, vane pumps have wide range of applications including fuel pumping, power steering system and automatic transmission system. Fluid behavior costs a lot to be seen inside the pump during operation experimentally however, predictive tools based on Computational Fluid Dynamics (CFD), has become a valid alternative approach to pump design and optimization. In this paper, CFD analysis for oil vane pump will be shown including different (number of vanes) models and different gap heights. The numerical model was built up with ANSYS (Fluent) using dynamic mesh code and it was validated by comparing the obtained numerical results with the experimental data of (four vanes) pump. The model gave a good agreement with the experiment results, with maximum deviation $<6 \%$ in the flow rate. The eight vanes pump model and the gap with a height of 0.1 $\mathrm{mm}$ gave the largest flow-rate and best performance as well.
\end{abstract}

\section{Keywords: CFD; vane pump; computational fluid dynamics; dynamic mesh; finite volume; turbulence model}

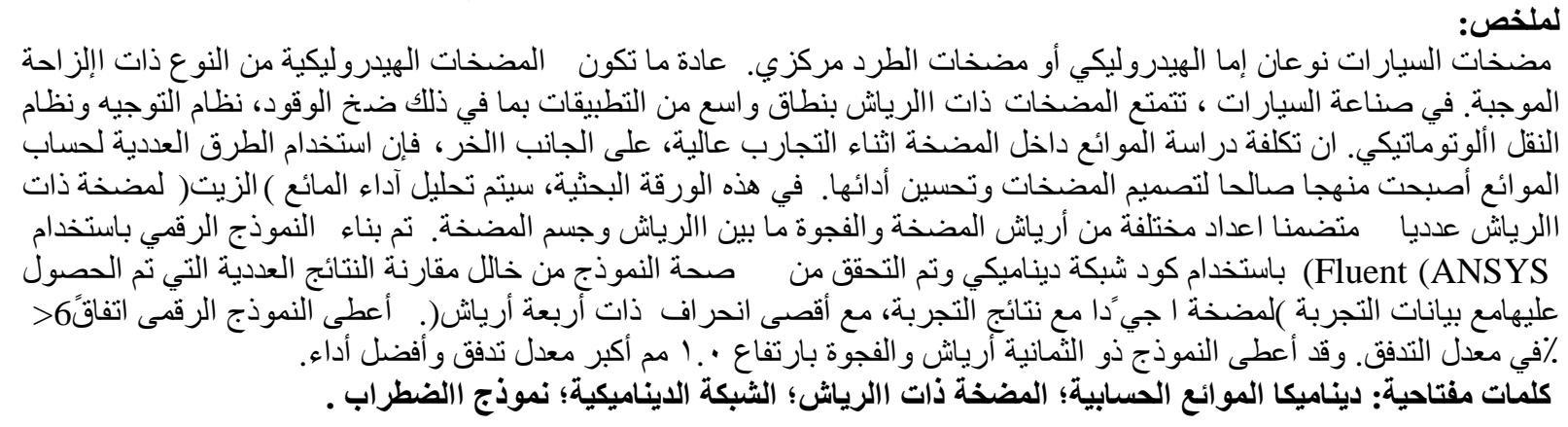

\section{INTRODUCTION}

Vane pumps are a type of fluid machines which works based on volumetric displacement. When this pump is working against a hydraulic resistance, fluid is transported from a low-pressure level (suction side of the pump) to a high-pressure level (pressure side of the pump) using a positive displacement principle (forced by the vanes). Generally, the pump consists of several chambers or cells which are mechanically coupled to a rotating shaft and periodically change their volume, while the shaft rotates [1]. 
Many numerical studies are performed on the vane pumps, but the most basic challenge is that the flow volume changes continuously over the time. Therefore, numerical solver must be able to deform and generate the mesh every time-step, as each mesh node displacement is composed of a solid body rotation and a radial translation.

Rancic [2] studied the influence of different port designs on decreasing the pressure pulsation on a balanced vane pump. A CFD two-dimensional model was developed and his obtained results were assessed and validated experimentally. He found that port modification and using metering grooves (trapezoidal and triangular), led to pressure pulsation reduction by about $24 \%$ compared to an initial design [2]. Pressure pulsation is the main noise source in the vane pump. It also produces low-pressure locations which could lead to originate cavitation. Using different geometries like (V-notch) in the inlet port of the pump is a good way to smooth the pressure variations, as demonstrated in [3]. Rana and Kumar [4] modelled a gear pump using CFD ANSYS Fluent version 14.0 in order to examine existing pump for working at 4 PSI delivery pressure which is required to operate punching machine for cooling purpose. Their obtained numerical results were compared with the experimental results and gave a good agreement in order to validate the numerical model. They concluded that the CFD tools could simulate several pump designs efficiently.

Cavitation simulation was performed using a code that has been developed to capture the gap shape between both the vane and stator with moving mesh by Zhang and $\mathrm{Xu}$ [5]. They investigated the influences of different vane tip radiuses on the cavitation area and flow rate of the vane pump. They examined the cavitation size due to different radii of the vane tip. Moreover, they found that the time averaged flow rate at outlet of pump was a bit larger in the case of small tip radius over a period.

A three-dimensional CFD analysis of a novel vane pump power split transmission (VPPST) is studied by Frosina et al [6]. The (VPPST) is a double-acting vane pump with two inlet chambers and two outlet chambers where the rotor and the ring contour are concentric. This study analyzed the output shaft power at different rotational pump speeds and pressures. Moreover, the influence of different gap heights between the vane tips and the ring were analyzed. This study illustrated that by increasing the gap, the leakage and the output power decreases.

The current paper focuses on the numerical modeling of an oil sliding vane pump with CFD three- dimensional code using ANSYS Fluent version 16.0, which can generate the mesh for different vanes number and different gap heights in order to illustrate the effect of the gap height on the flow-rate. In addition, the performance of the different (number of vanes) models and different gap heights. The turbulence model $(\mathrm{K}-\omega)$ SST was used. This model was validated by comparing obtained numerical results with the experimental data.

\section{EXPERIMENTAL SETUP}

An experiment was conducted using a four vanes pump with volumetric displacement equals 38 $\mathrm{cm}^{3} / \mathrm{rev}$. at different rotational speeds, getting the flow-rate and pressure. This pump consists of a rotor having radial slots positioned off-center in a housing bore. Both rotor and housing are circulars with diameters $D_{1}=64 \mathrm{~mm}$ and $D_{2}=72 \mathrm{~mm}$, respectively and width $=45 \mathrm{~mm}$. Four vanes with a thickness of $3.2 \mathrm{~mm}$ are fit closely in the rotor slots to slide in and out as the rotor turns. Pumping action is caused by both the expanding and contracting volumes contained by the rotor, vanes, and housing. A two-dimensional drawing of the pump is shown in Figure (1). 


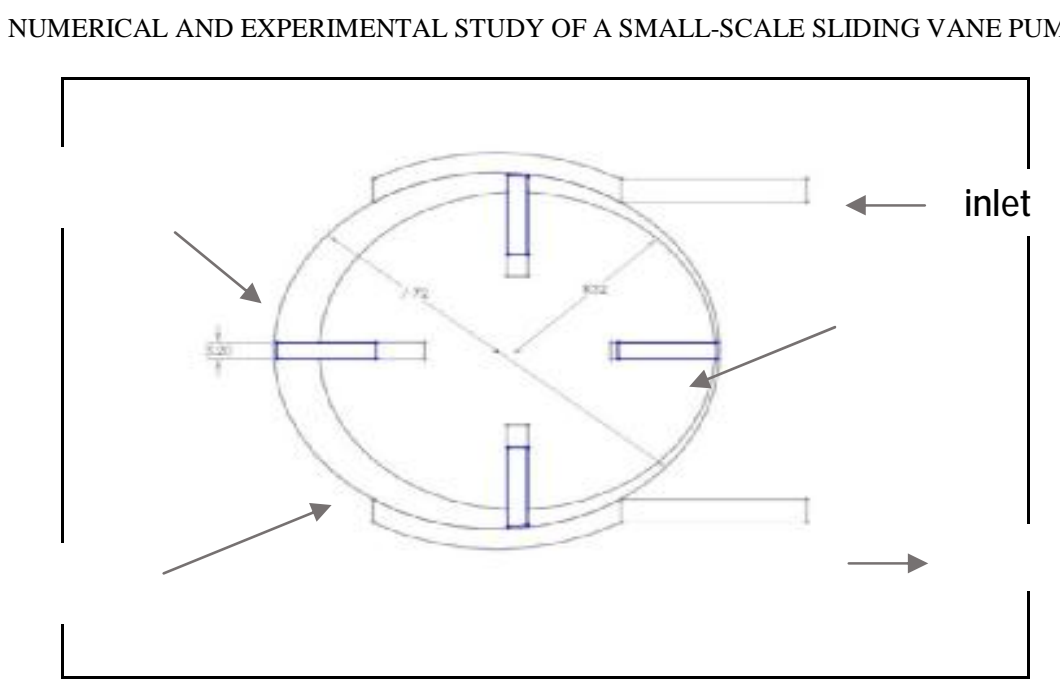

Figure 1. A Two-Dimensional Vane Pump.

The test rig setup is a closed circuit comprises of a vane pump (1) which draws oil from a tank (2). The pump is driven by an electric motor which is connected to the pump by mechanical coupling. A frequency inverter is connected to the motor in order to vary the rotational speed of the pump. The flow is delivered by the pump pass through a delivery pipe having a pressure gauge (3), flow meter (4) and control valve (5) by which the oil pressure in the delivery line can be changed then the oil back to the oil tank. The test rig and the hydraulic schematic are shown in Figure (2).
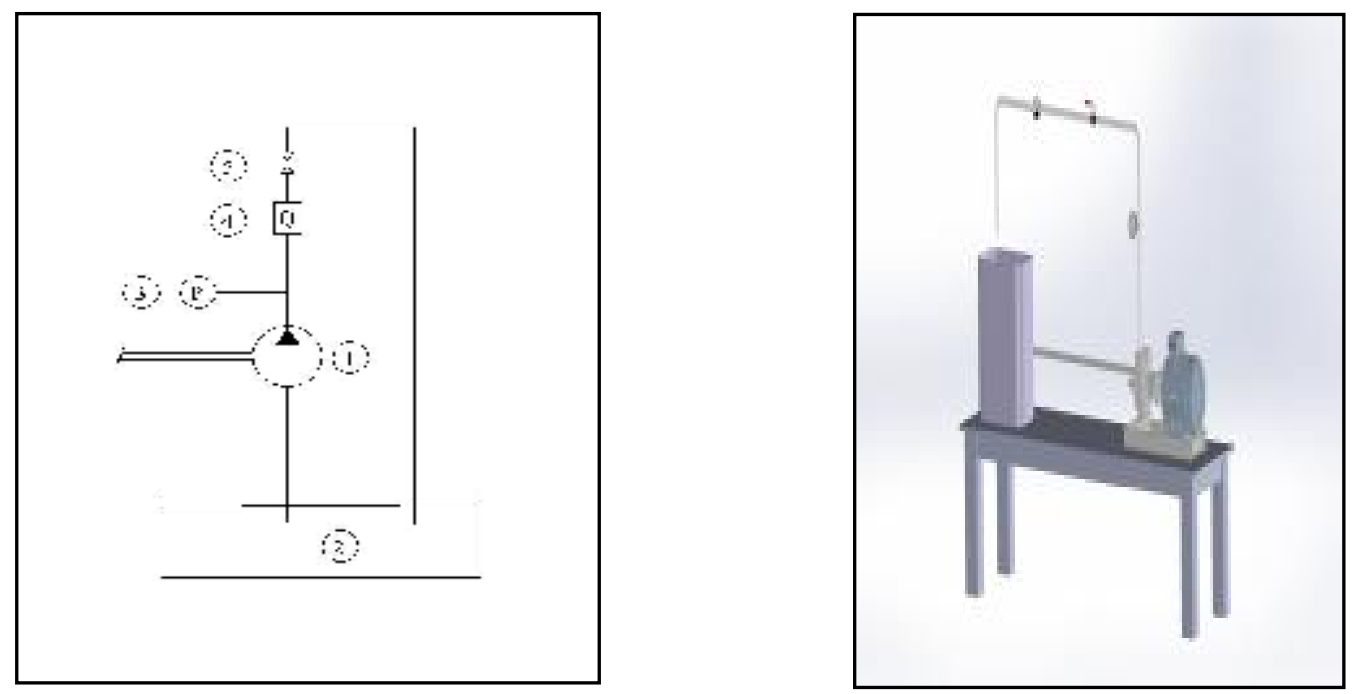

Figure 2. Pump test rig.

Three rotational speeds for the pump were examined for different pressures corresponding to each one which allowed determining a characteristic map, depicted in Figure (3), in terms of pressure versus flow-rate curves. 
NUMERICAL AND EXPERIMENTAL STUDY OF A SMALL-SCALE SLIDING VANE PUMP

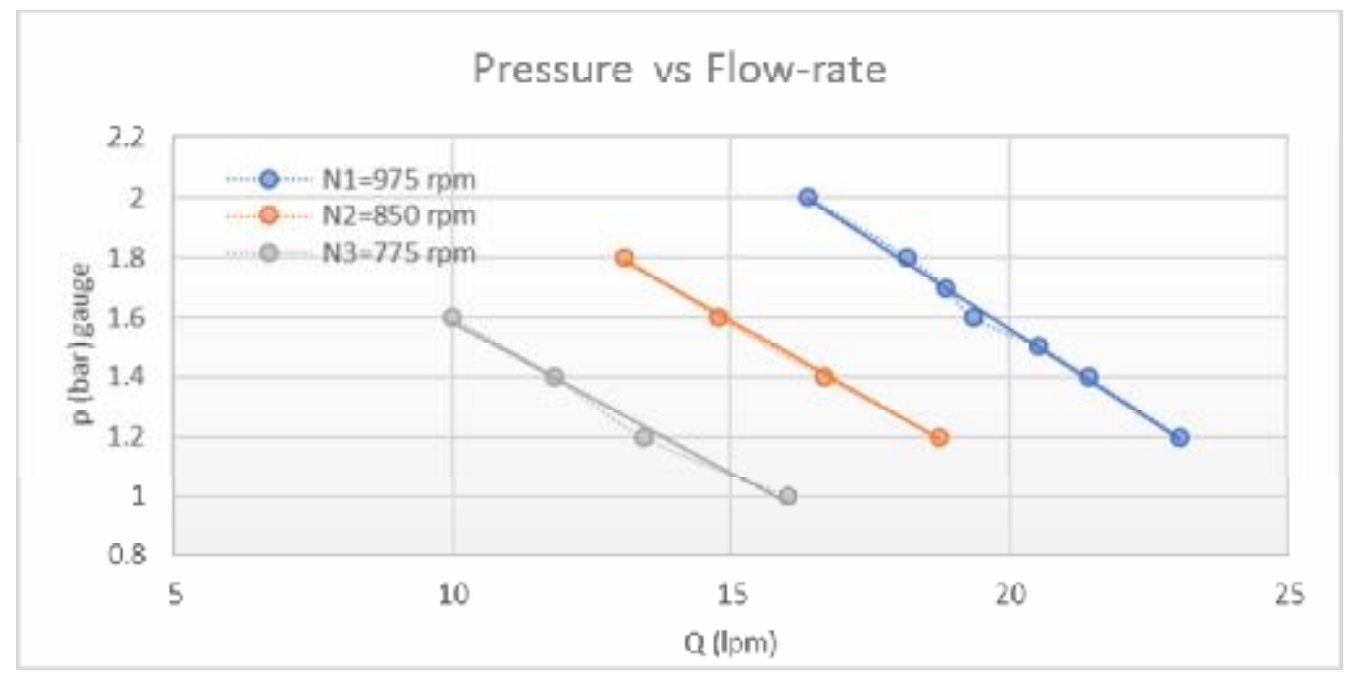

Figure 3. Experimental Results Pressure vs Flow-rate.

The numerical model will be validated by comparing its simulated results with the curve of 975 rpm.

\section{Computational Method}

A detailed three-dimensional model was generated in order to perform the flow simulations using ANSYS work bench (design modeler) version 16.0.

\subsection{Numerical Model}

The geometry included stationary zones (inlet and outlet pipes) and moving deformation zones (rotating chambers). Variant number of models includes a different number of vanes and gap heights were used. The pump model is shown in Figure (4).

\subsection{Mesh Generation and Dynamic Mesh}

In order to perform the numerical modeling, the model was meshed with fully structured grid (Hexahedron) using ANSYS Fluent with minimum size $=1.9383 \mathrm{e}-5 \mathrm{~m}$, maximum size $=3.8767 \mathrm{e}-$ $3 \mathrm{~m}$, growth rate $=1.2$ and minimum orthogonal quality $=3.00646 \mathrm{e}-01$. The structured grid was adopted to reduce the numerical errors due to less skewness and overlaps. Moreover, it improves the system speed and accuracy. A grid independent test was performed by running the simulation case many times starting with coarse mesh (150,000 elements) ending with very fine mesh $(1,700,000$ elements). It is noted that the mesh is independent at $(1,000,000$ elements) as shown in Figure (5).

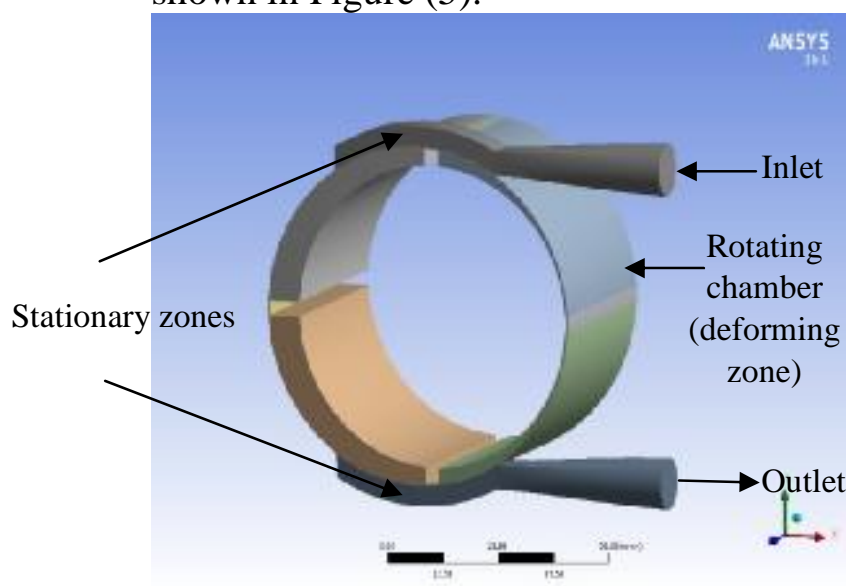

(a)

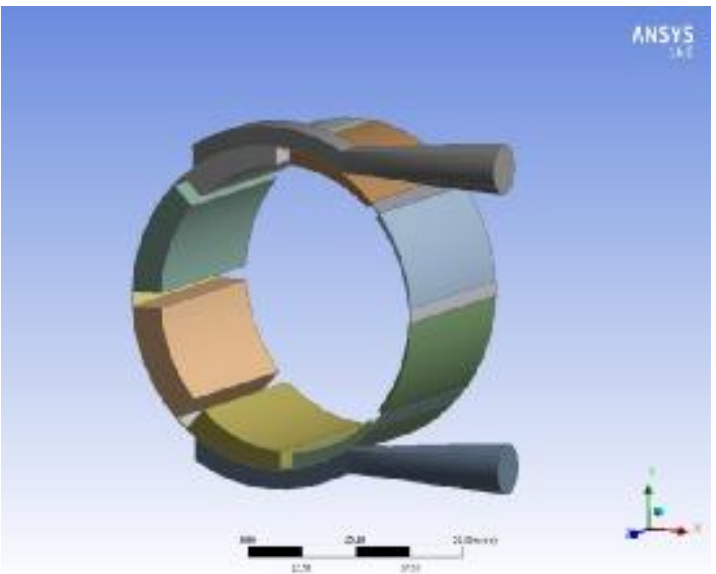

(a)

Figure 4. The pump model; a) four-vane model b) eight-vane model. 


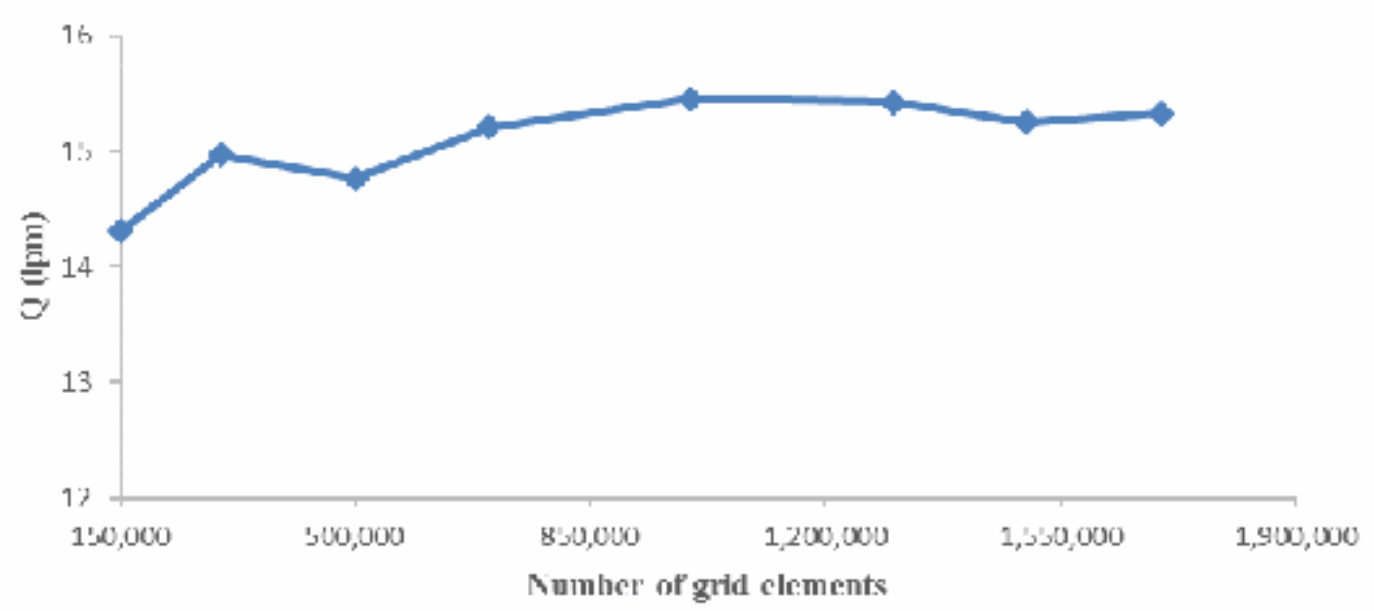

Figure 5. Grid independency test.

ANSYS-Fluent dynamic mesh capability was used to model the change in-time-shape of rotor chambers. Both the motion of the mesh nodes and the vane were described by a userdefined function (UDF). This mesh motion is a function of chamber eccentricity, revolution speed and the rotor/ case shape [7]. For positive displacement pumps, and as a result of existing of two different zones (one of them is stationary and the other is moving and deforming), it is necessary to use a moving / sliding methodology whereby the stationary and moving zones are meshed separately. Each zone connects to the other via a non-conformal mesh interface, which, due to motion and deformation is updated at each time-step [8]. The model mesh and zones are illustrated in Figure (6).
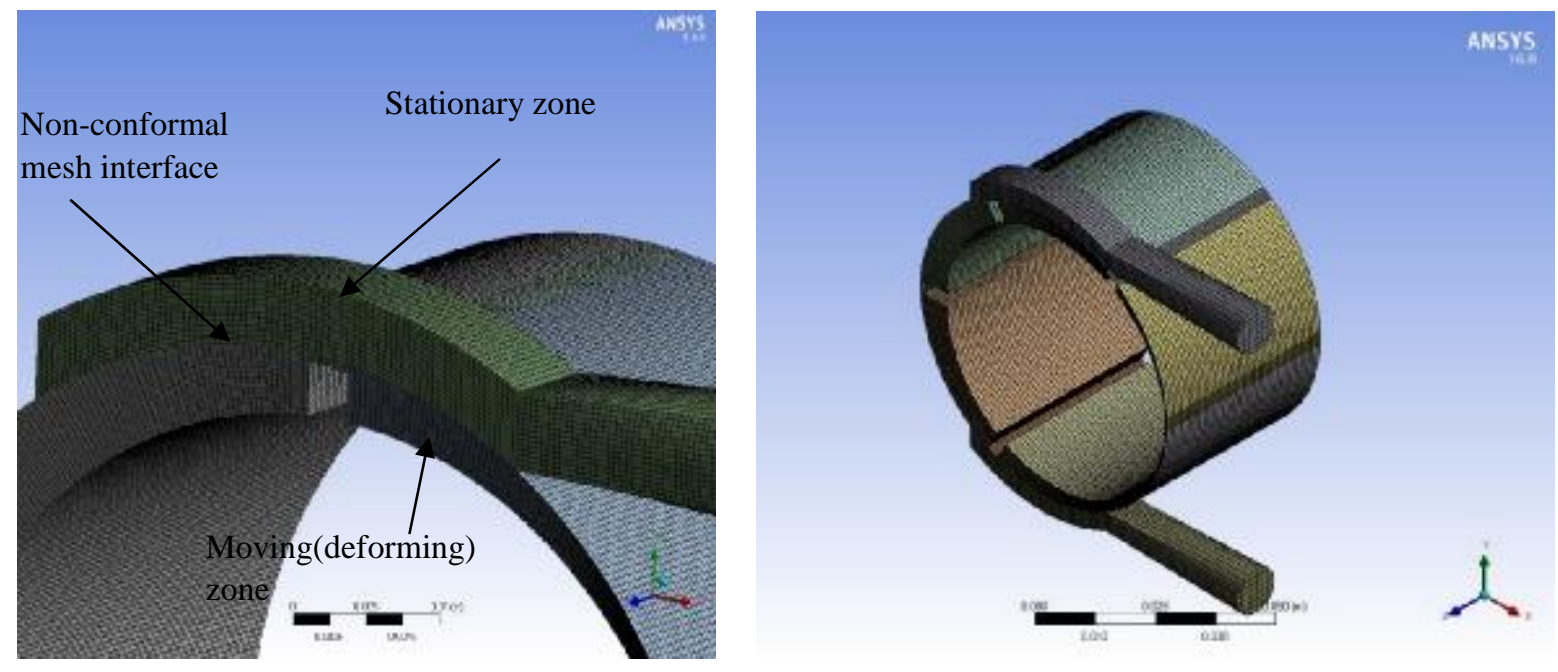

Figure 6. The model with structured mesh.

\subsection{Boundary Conditions}

A set of boundary conditions were obtained from the experimental data originated by laboratory experiment bench to validate the numerical model by comparing the results as following:

a) A total pressure of 0 -gauge, turbulent intensity of $5 \%$ and hydraulic diameter of $11 \mathrm{~mm}$ were defined at the pump inlet. 
b) A set of static pressure starting with 1.2-gauge bar ending with 2-gauge bar, turbulent intensity of $5 \%$ and hydraulic diameter of $11 \mathrm{~mm}$ were defined at the pump outlet.

c) The working fluid that was used in the experiment was oil with density of $891 \mathrm{~kg} / \mathrm{m}^{3}$ and dynamic viscosity of $0.0163053 \mathrm{~kg} / \mathrm{m} . \mathrm{s}$.

d) The rotational speed for the pump was set to $975 \mathrm{rpm}$, equal to that of the experimental data.

\subsection{Numerical Details and Governing Equations}

Commercial package ANSYS-Fluent (version 16.0) was selected to perform the finite volume, transient, three-dimensional Reynolds Average Navier-stokes (RANS) approach for flow modeling [9]. A pressure-based solver with pressure-velocity coupling (PISO) scheme, which is normally chosen for transient calculations, was used to solve the governing equations. A spatial discretization data which were chosen are as follow: standard for pressure, second order upwind for density and momentum, first order upwind for turbulent kinetic energy and specific dissipation rate. Navier-stokes continuity and momentum conservation equations for Newtonian fluids are given as follow [3]:

$$
\begin{gathered}
\frac{\partial}{\partial t}(\rho)+\nabla \cdot(\rho U)=0 \\
\frac{\partial}{\partial t}(\rho U)+\nabla \cdot(\rho U U)=-\nabla P+\nabla \cdot\left(T+T^{T u r b}\right)
\end{gathered}
$$

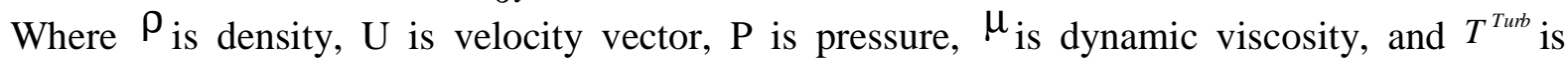
turbulent stress tensor. The convective term ( $\rho U U)$ represents a differential balance of momentum, on a control volume. The right-hand side of equation (2) represents the summation of external forces: pressure and shear stresses [3].

Three complete revolutions were computed in all simulations in order to assure obtaining the repeatable pattern, with 1 deg time-step which is found to be sufficient to resolve timedependent features and to get the real behavior of transient changes besides maintaining the numerical solver stability.

\subsection{Turbulence Model}

Two turbulence models, $\mathrm{k}-\varepsilon$ realizable and shear stress transport (SST) k- $\omega$ were used. The (SST) k- $\omega$ turbulent model which gives a good behavior in both adverse pressure gradients and separating flow, [add reference]. This model was found to be the most comparable to the experimental data and was used in all simulations.

The eddy viscosity model is used for the Reynolds stress term to close the equation set.

$$
\begin{gathered}
R_{i j}=-\rho \overline{u_{i}^{\prime} u_{j}^{\prime}}=2 \mu_{t} S_{i j}-\frac{2}{3}\left(\mu_{t} \frac{\partial u_{k}}{\partial x_{k}}+\rho k\right) \delta_{i j} \\
S_{i j}=\frac{1}{2}\left(\frac{\partial u_{i}}{\partial x_{j}}+\frac{\partial u_{j}}{\partial x_{i}}\right)
\end{gathered}
$$

Where $S_{i j}$ is the deformation rate tensor, $\delta_{i j}$ is the Kronecker operator, $\mathrm{k}$ is a turbulent kinetic energy and $\mu_{t}$ is the turbulent viscosity.

The shear stress transport (SST) $\mathrm{k}-\omega$ model is a hybrid two-equation model that combines the advantages of both k- $\varepsilon$ and k- $\omega$ models. The SST model can be switched to a k- $\varepsilon$ model in the free-stream avoiding the common k- $\omega$ problem and its over sensitivity to the inlet free-stream turbulence properties and performs much better than k- $\varepsilon$ model for boundary layer flows.

Both the turbulence kinetic energy $\mathrm{k}$ and the specific dissipation rate $\omega$ are obtained from the following transport equations [5]: 


$$
\begin{gathered}
\frac{\partial}{\partial_{t}}(\rho k)+\frac{\partial}{\partial x_{i}}\left(\rho u_{i} k\right)=\tau_{i j} \frac{\partial U_{i}}{\partial x_{j}}-\beta^{*} k \rho \omega+\frac{\partial}{\partial x_{j}}\left[\left(\mu+\frac{\mu_{t}}{\sigma_{k}}\right) \frac{\partial k}{\partial x_{j}}\right] \\
\frac{\partial}{\partial_{t}}(\rho \omega)+\frac{\partial}{\partial x_{i}}\left(\rho u_{i} \omega\right)=\frac{\gamma}{v_{t}} \tau_{i j} \frac{\partial U_{i}}{\partial x_{j}}-\beta \rho \omega^{2}+\frac{\partial}{\partial x_{j}}\left[\left(\mu+\frac{\mu_{t}}{\sigma_{\omega}}\right) \frac{\partial \omega}{\partial x_{j}}\right]+2 \rho\left(1-F_{1}\right) \sigma_{\omega 2} \frac{1}{\omega} \frac{\partial k}{\partial x_{j}} \frac{\partial \omega}{\partial x_{j}} \\
\mu_{t}=\rho \frac{k}{\omega}
\end{gathered}
$$

Where $\sigma_{k}, \beta^{*}, \gamma, \beta, F_{1}$ are the empirical constants obtained from theoretical analysis combined with experimental data.

\section{Numerical results and discussion}

\subsection{Validation of the numerical model}

The values of the flow-rate from numerical modeling at different pressures were compared with the experimental data at certain speed as presented in Figure (7). It is apparent that the numerical results have a good agreement and very similar to the experimental results, with maximum deviation $<6 \%$ in the flow rate at the same pressure head. As a result, this confirms the validity of the numerical model.

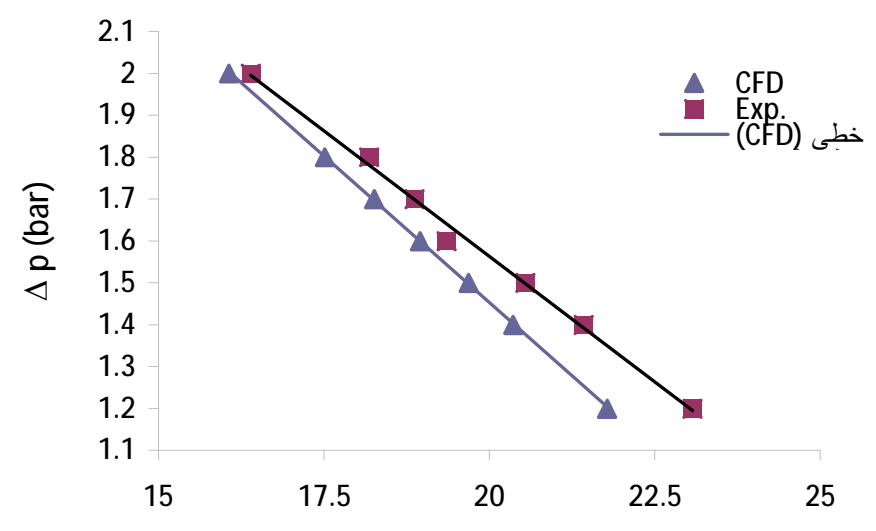

Flow rate (Ipm)

\subsection{Numerical Results}

Figure 7. Validation of the numerical results.

In the current paper, the analysis was focused in three aspects; the effect of the gap height between the vane tip and the outer casing on the flow-rate, the effect of number of rotor vanes models on flow-rate and the overall pump efficiency and performance. The results were analyzed at different speeds and pressures.

4.2.1 Effect of gap heigh Simulations were performed for four vanes model to determine the pump characteristic map, in terms of pressure versus flow-rate curves at the outlet, three gap heights $(0.5,0.3$ and $0.1 \mathrm{~mm})$ for two rotational pump speeds (2000 and $3000 \mathrm{rpm}$ ) as shown in Figure (8). 


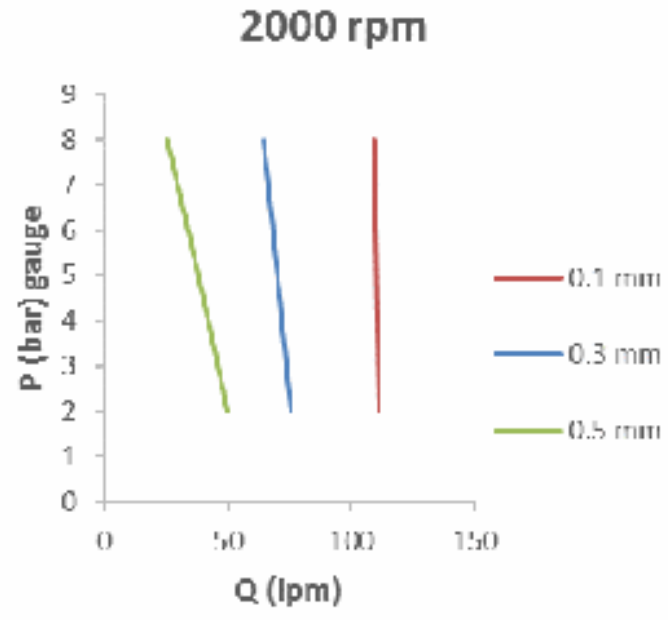

(b)

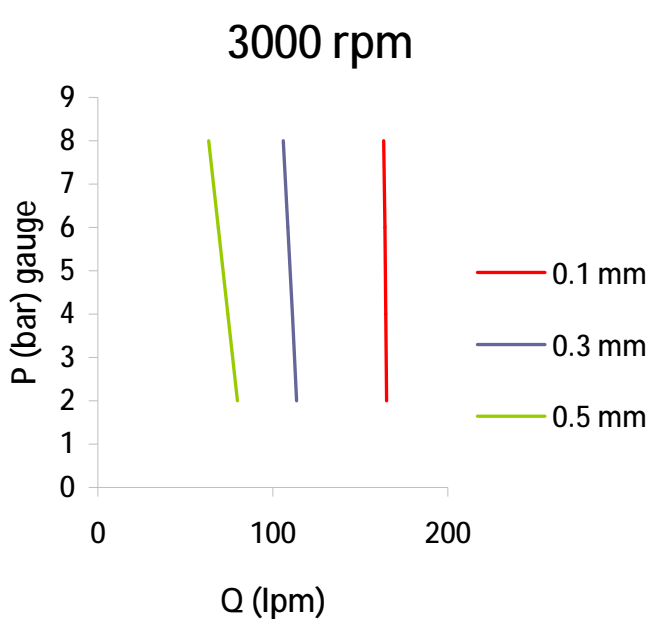

(b)

Figure 8. Pressure vs Flow-rate; a) 2000 rpm b) 3000 rpm.

Figure (8, a and b) shows the effect of three gap heights on output flow rate, where there is a significant increase between the gaps of $0.5,0.3$ and $0.1 \mathrm{~mm}$. As shown in Figure (8), it is obvious that the gap height affects the flow-rate. Consequently, the more increase in the gap height the lower outlet flow-rate. In addition, the curves slope is decreased by decreasing the gap height which leads to less leakage in the flow but more friction between the vane tip and the outer casing.

Moreover, the pressure in the pump chambers is decreased by increasing the gap height as shown in Figure (9).

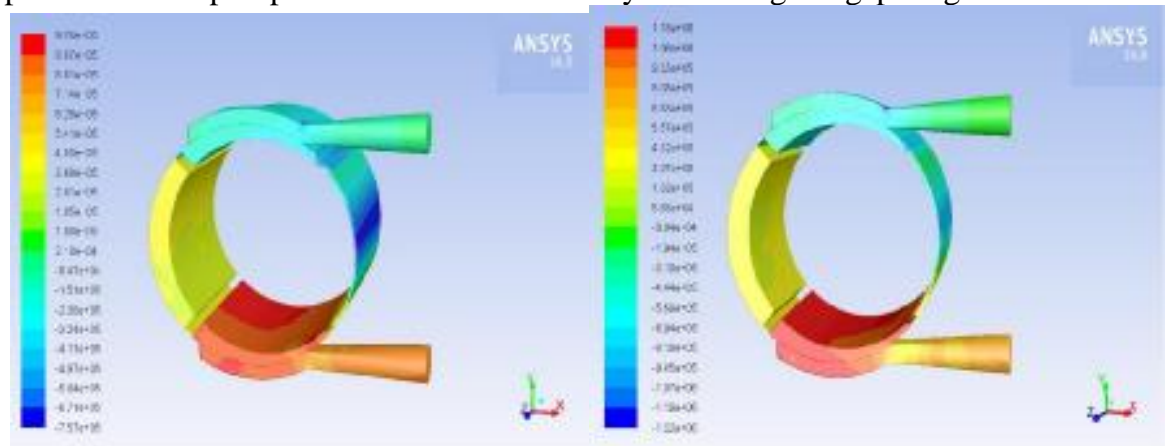

(a)

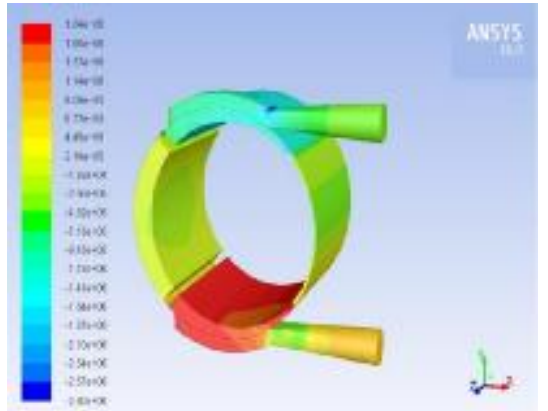

(b)

(c)

Figure 9. Pressure in pump chambers at crank angle of 225 deg., 8 bar outlet and $3000 \mathrm{rpm}$ a) $0.5 \mathrm{~mm}$ gap b) $0.3 \mathrm{~mm}$ gap c) $0.1 \mathrm{~mm}$ gap. 
Using the numerical model, the output power has been analyzed too using equation (6). Figure (10) presents the numerical results per one revolution obtained at two speeds as a function of the shaft position at 8 bars.

$$
P_{\text {out }}=p_{\text {out }} * Q_{\text {out }}
$$

Figure (10) demonstrates the great influence of the gap height on the output power, showing that the ripples and the value of the power decrease by increasing the gap height which affects directly on the total performance.

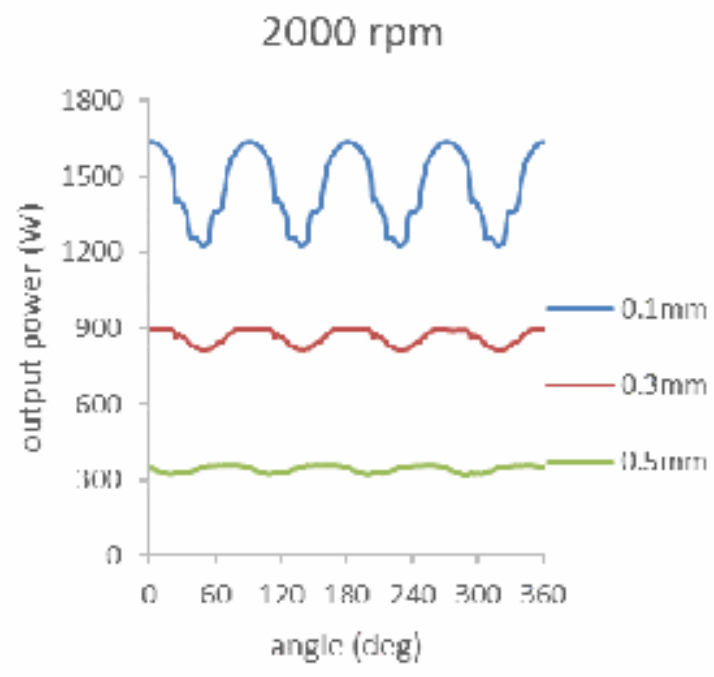

(d)

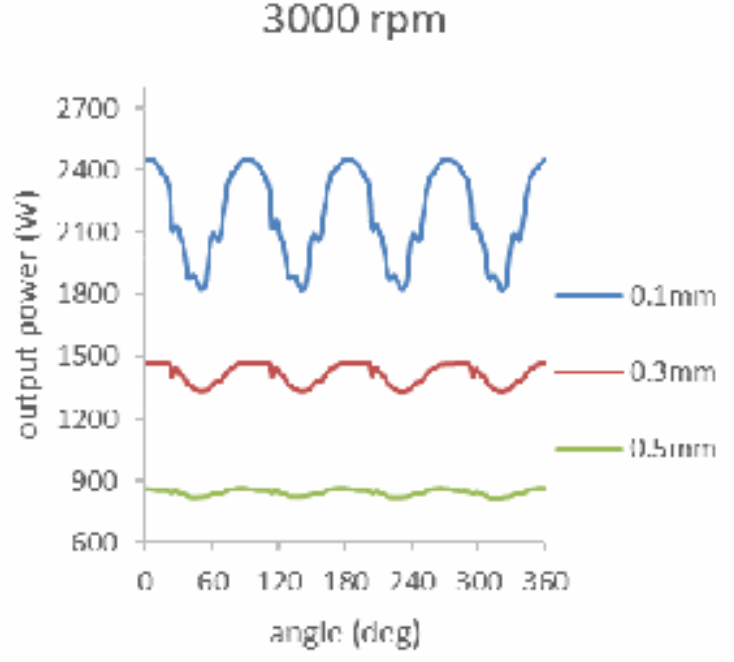

(b)

Figure 10. output power at different gap heights a) $2000 \mathrm{rpm}$ b) $3000 \mathrm{rpm}$.

\subsubsection{Effect of number of rotor vanes}

Another factor was taken into consideration in simulations which is the number of vanes. The pump characteristic map, in terms of pressure versus flow-rate curves at the outlet, for three models having (4, 6 and 8 vanes) at a gap height of $0.3 \mathrm{~mm}$ were modeled and examined for two rotational pump speeds (2000 and 3000rpm) as shown in figure (11).

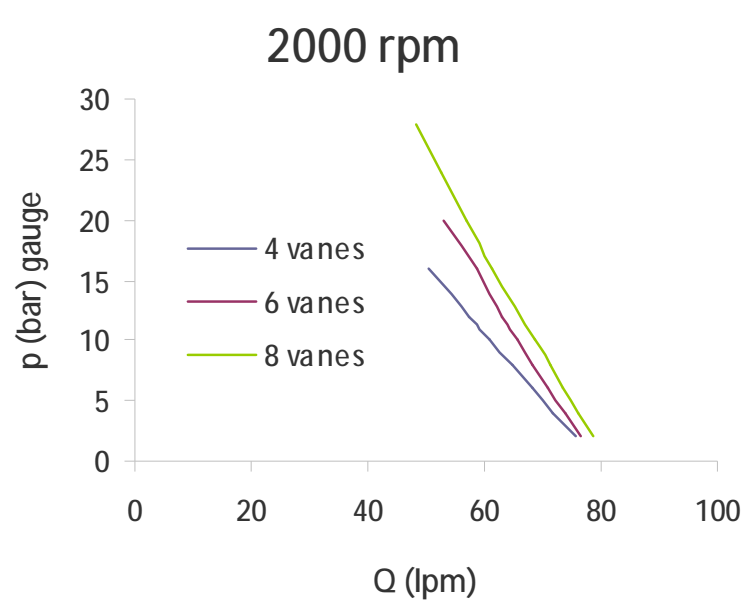

(e)

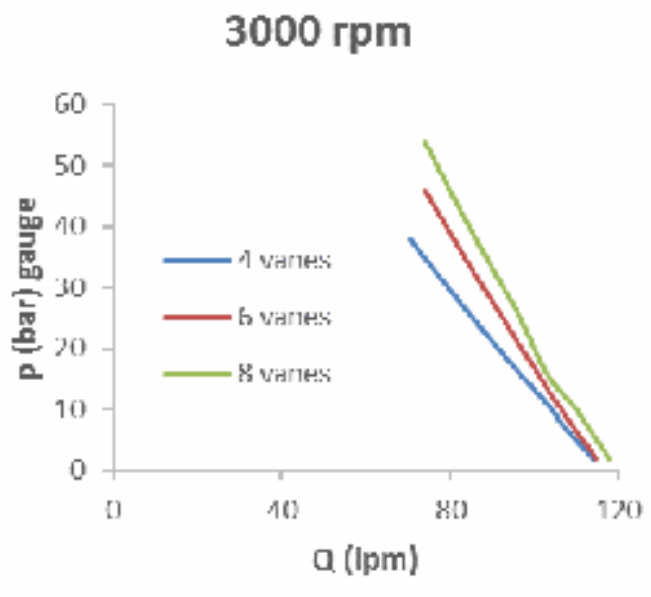

(b)

Figure 11. Pressure vs Flow-rate; a) 2000 rpm b) 3000 rpm. 
Figure (11, a and b) shows at the output flow-rate at different rotational pump speeds and different vanes number. It is apparent that by increasing the number of vanes, the flow-rate increases. In ( $a$ and $b$ ), the effect of the number of vanes is obvious in flow-rate increasing between 4, 6 and 8 vane models in the output flow-rate. The curves slope in figure (11) reduces by increasing the number of vanes, which prevent the flow inner leakage.

\subsubsection{Overall pump efficiency $\&$ performance}

The overall pump efficiency and performance curves for three models (4, 6 and 8 vanes) at gap height $0.3 \mathrm{~mm}$, in terms of efficiency, discharge coefficient, head coefficient, and power coefficient are presented to illustrate the different model's performance. These coefficients are calculated as follow:

$$
\begin{array}{rlr}
\eta_{\text {overall }}=\frac{p_{\text {out }} * Q_{\text {out }}}{b p} & \text { (7), } & C_{Q}=\frac{Q}{\omega D^{3}} \\
C_{H}=\frac{g H}{\omega^{2} D^{3}} & \text { (9), } & C_{P}=\frac{b p}{\rho \omega^{3} D^{5}}
\end{array}
$$

Where $\mathrm{H}$ is the head, $\mathrm{D}$ the outer diameter, bp is the brake power and $\omega$ is the angular velocity (in radians per second).

The normalized efficiency versus capacity coefficient was calculated for two rotational pump speeds (2000 and $3000 \mathrm{rpm}$ ) and presented in figure (12 a and b). Figure (12 a and b) shows the effect of vanes number on the overall pump efficiency. It is clear that the pump with 8 vanes gives the best efficiency compared to (4 and 6 vanes) curves.

Another performance curves, which are head coefficient versus capacity coefficient and power coefficient versus capacity coefficient were calculated and presented for three rotational pump speeds $(2000,2500$ and $3000 \mathrm{rpm})$ in figures $(13,14$ and 15).

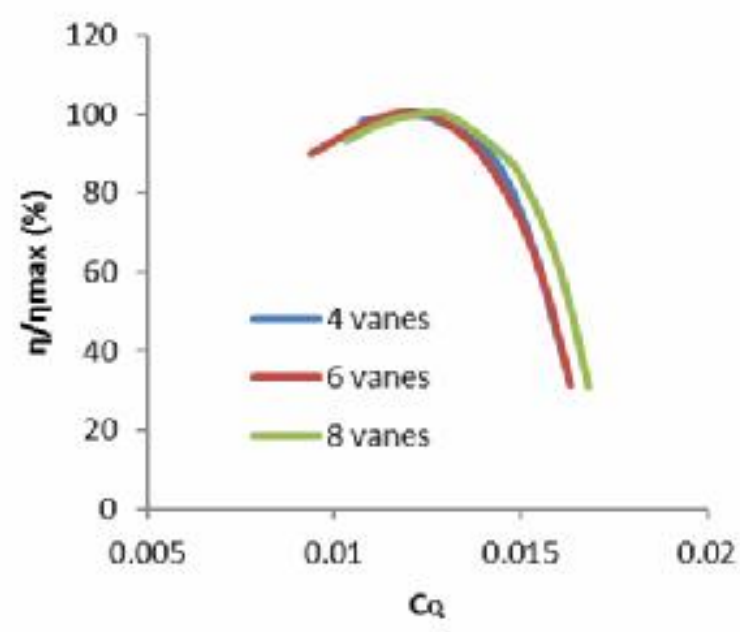

(a)

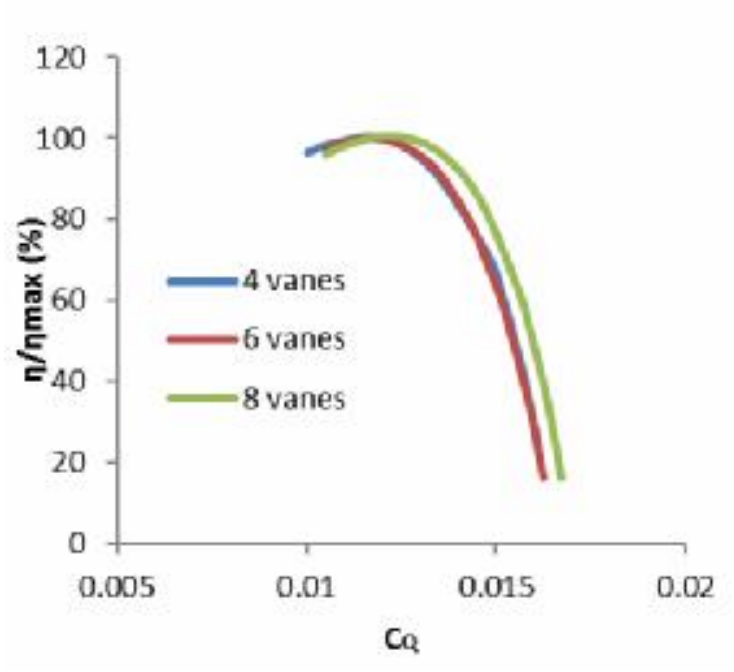

b)

Figure 12. The ratio of pump efficiency to Max efficiency vs discharge coefficient for the three models at $(a=2000 \mathrm{rpm}$ and $b=3000 \mathrm{rpm})$ 
NUMERICAL AND EXPERIMENTAL STUDY OF A SMALL-SCALE SLIDING VANE PUMP

(a)

$C_{p}$ vs $C_{1,}, 4$ vanes

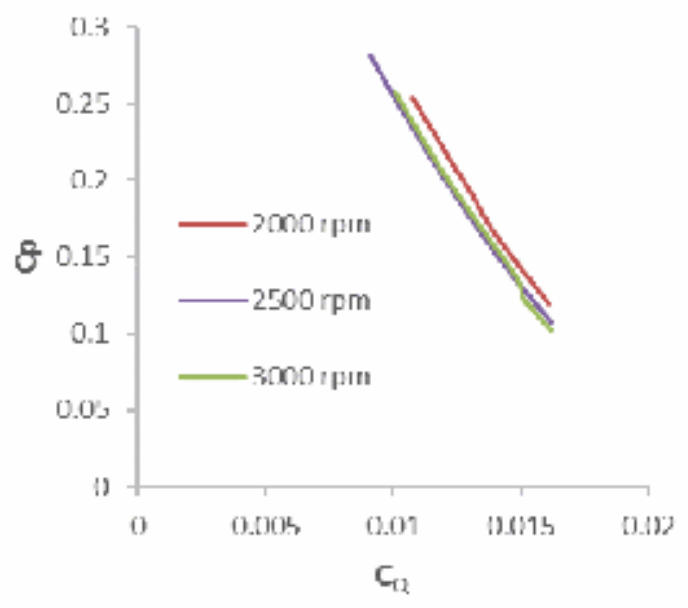

(b)
$\mathrm{C}_{11}$ vs $\mathrm{C}_{\mathrm{u}}, 4$ vanes

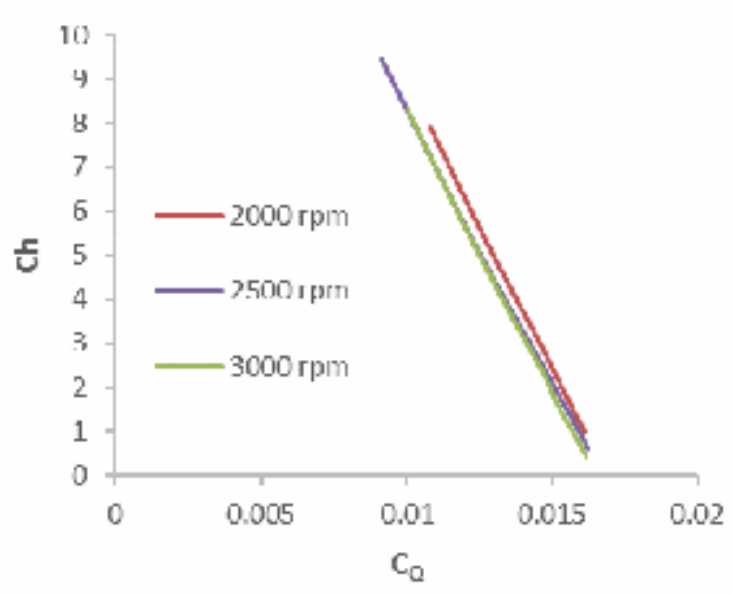

(b)

Figure 13. Four vanes model; a) power coefficient vs capacity coefficient b) head coefficient vs capacity coefficient.

$$
C_{P} \text { vs } C_{Q}, 6 \text { vanes }
$$

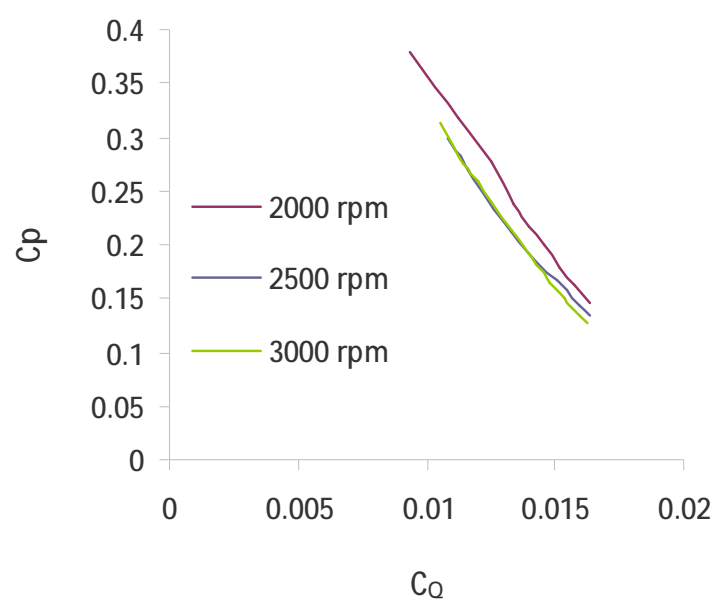

(a)
$\mathrm{C}_{11}$ vs $\mathrm{C}_{2,}, 6$ vanes

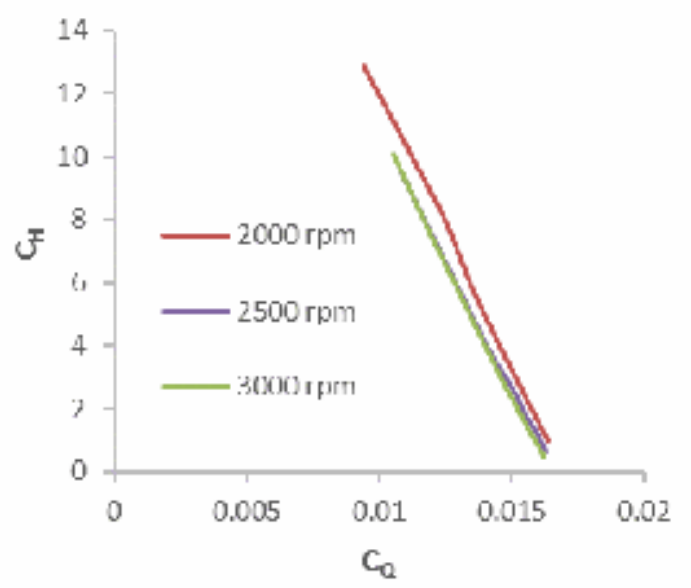

(b)

Figure 14. Six vanes model; a) power coefficient vs capacity coefficient b) head coefficient vs capacity coefficient. 


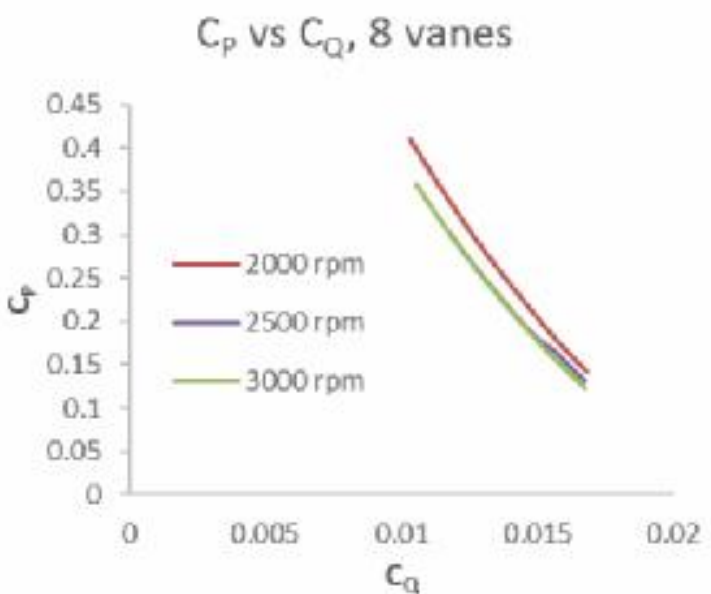

(a)

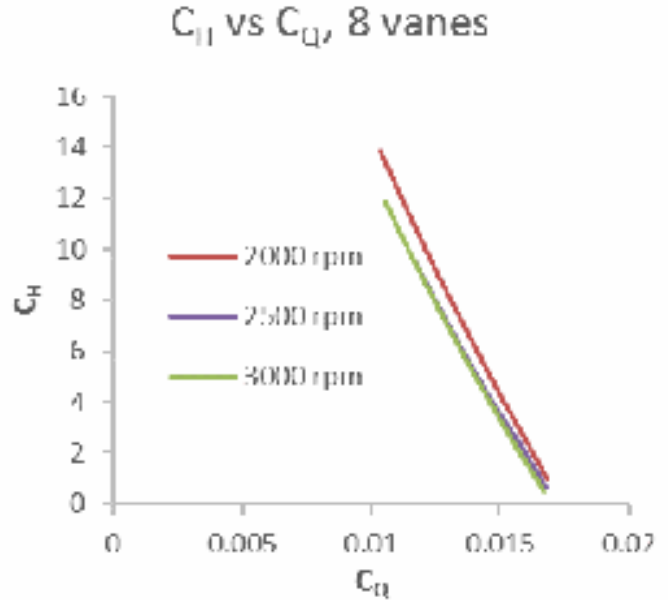

(b)

Figure 15. Eight vanes model; a) power coefficient vs capacity coefficient b) head coefficient vs capacity coefficient.

\section{CONCLUSIONS}

In the present paper, a parametric study for a vane pump using CFD modeling was conducted with experimental validation. The model similar to the one used in the experimental work was conducted and validated with a good agreement of the flow-rate with less than $6 \%$ error. The study analyzed the effect of the gap height and its effect on the flow-rate and therefore the output power at different rotational pump speeds and pressures by varying three gap heights between the vane tip and the outer casing. The gap height of $0.1 \mathrm{~mm}$ gave the best performance and flow-rate. Moreover, three models with (4, 6 and 8 vanes) were modeled. The characteristic map and the normalized efficiencies were determined at different speeds and pressures, and the eight vanes model gave the best flow-rate and therefore the output efficiency. In conclusion, CFD tools found to be reliable in simulating several pump designs and optimize it efficiently.

\section{REFERENCES}

1. Hain-Würtenberger, S. (2007) Simulation of cavitating flow in vane pumps. $3^{\text {rd }}$ European Automotive CFD Conference, pp.285-293.

2. Rancic, S. (2014) Reduction of pressure pulsations on automotive transmission oil vane pump. M.Sc. thesis, Department of Mechanical Engineering.

3. Takemori, C. et al. (2005) Numerical simulation of oil flow in a power steering pump. SAE Exhibition.

4. Rana, D. Kumar, N. (2014). Experimental and computational fluid dynamic analysis of external gear pump. International Journal of Engineering Development and Research, volume 2, pp. 2474-2478.

5. Zhang, Q. Xu, X. (2014) Numerical simulation on cavitation in a vane pump with moving mesh. ICCM Conference.

6. Frosina, E. et al. (2015) Vane pump power split transmission: three-dimensional computational fluid dynamics modeling. FPMC Conference.

7. Brusiani, F. et al. (2009) Evaluation of air/cavitation interaction inside a vane pump. 4th European Automotive Simulation Conference.

8. Frosina, E. et al. (2014) A tridimensional CFD analysis of the oil pump of a high performance motorbike engine. 68th Conference of the Italian Thermal Machines Engineering Association. pp. 938-948.

9. Gad-el-Hak, I. et al. (2017). 3D numerical modeling of zeotropic mixtures and pure working fluids in an ORC turbo-expander. International Journal Turbomachinery Propulsion and Power, vol. 2. 